\title{
Evaluation of carcinoid heart disease using delayed enhancement imaging
}

\author{
M. Hrabak-Paar $\cdot$ R. Štern-Padovan
}

Received: 23 October 2010/Accepted: 30 November 2010/Published online: 12 December 2010

(C) Royal Academy of Medicine in Ireland 2010

We read with interest the case report by Martos et al. [1] entitled "Cardiac carcinoid: tricuspid delayed hyperenhancement on cardiac 64-slice multidetector CT and magnetic resonance imaging", published in the Irish Journal of Medical Science. Imaging characteristics of this rare disorder can be found in the literature; especially those features obtained using echocardiography and magnetic resonance imaging (MRI). The main morphological characteristics of the disease are thickening and restricted mobility of the tricuspid leaflets and subvalvular apparatus with consequent tricuspid stenosis and insufficiency. Although Martos et al. $[2,3]$ cite papers where characteristics of tricuspid-delayed enhancement were previously described, after careful reading we did not find any of them in the cited articles.

Delayed-MRI enhancement can delineate zones of fibrous tissue 10-30 min after intravenous administration of gadolinium chelate contrast agent [4]. Similar depiction of scar and fibrous tissue can be obtained using computed tomography by delayed scanning after intravenous administration of iodinated contrast material [5]. In the case report Martos et al. describe delayed enhancement of tricuspid annulus in a patient with carcinoid heart disease, but, unfortunately, they did not give their explanation why they observed late enhancement in this region. We believe that in patients with carcinoid heart disease delayed enhancement should be seen only in endocardial region of the right cardiac chambers including tricuspid leaflets. This type of late enhancement would represent distribution of endocardial

M. Hrabak-Paar $(\bowtie) \cdot$ R. Štern-Padovan Department of Diagnostic and Interventional Radiology, University Hospital Center Zagreb,

University of Zagreb School of Medicine,

Kispaticeva 12, 10000 Zagreb, Croatia

e-mail: majahrabak@gmail.com fibrous deposits that can be seen on pathological specimens. Considering that tricuspid annulus consists mainly of fibrous tissue, we believe that its late enhancement could be physiological, rather than related to carcinoid heart disease.

For better understanding of the case report, we would like to add that figures $3 \mathrm{~B}$ and $4 \mathrm{~A}$ were mixed, so that figure $3 \mathrm{~B}$ represents MDCT exam and figure 4A delayed enhancement on MRI examination. Furthermore, references 5 and 6 are the same with incorrectly spelled last name of the first author in the reference 6 .

\section{References}

1. Martos R, Ridge C, Quinn M, Dodd J (2010) Cardiac carcinoid: tricuspid delayed hyperenhancement on cardiac 64-slice multidetector CT and magnetic resonance imaging. Ir J Med Sci 179:447-449. doi:10.1007/s11845-008-0273-5

2. Mollet NR, Dymarkowski S, Bogaert J (2003) MRI and CT revealing carcinoid heart disease. Eur Radiol 13:14-18. doi:10.1007/s00330-002-1806-3

3. Bastarrika G, Cao MG, Cano D, Barba J, de Buruaga JD (2005) Magnetic resonance imaging diagnosis of carcinoid heart disease. J Comput Assist Tomogr 29:756-759. doi:10.1097/01.rct. 0000181724.69597.69

4. Vogel-Claussen J, Rochitte CE, Wu KC, Kamel IR, Foo TK, Lima JAC, Bluemke DA (2006) Delayed enhancement MR imaging: utility in myocardial assessment. RadioGraphics 26:795-810. doi: 10.1148/rg.263055047

5. Krombach GA, Niendorf T, Günther RW, Mahnken AH (2007) Characterization of myocardial viability using MR and CT imaging. Eur Radiol 17:1433-1444. doi:10.1007/s00330-0060531-8 